\title{
Uso de jardins flutuantes na remediação de águas superficiais urbanas poluídas
}

O enriquecimento por nutrientes em corpos hídricos que causam a eutrofização é um dos grandes problemas das águas superficiais das bacias urbanas, onde este processo é consequência principalmente da poluição por despejos de efluentes sem tratamento. Tendo em vista a necessidade do desenvolvimento sustentável das cidades, surge a procura por alternativas para o tratamento dessas águas poluídas que possam atuar de forma harmônica com a paisagem urbana. Desta forma este trabalho tem como objetivo a construção de um sistema de jardins flutuantes capaz de remediar as águas eutrofizadas de um pequeno açude localizado no Campus Sede da Universidade Federal de Campina Grande - PB ( $\left.35^{\circ} 54^{\prime} 30^{\prime \prime} 0,7^{\circ} 12^{\prime} 58^{\prime \prime} \mathrm{S}\right)$. 0 experimento foi realizado numa área de $400 \mathrm{~m}^{2}$ de espelho d'água e a montagem do sistema de jardins foi dividida em três etapas, atingindo no final da terceira etapa, uma cobertura de área superficial de aproximadamente $10 \%$. As estruturas modulares foram construídas de bambu e paletes, sendo utilizadas diferentes espécies de plantas aquáticas e ornamentais e substrato orgânico de fibra de coco. $\mathrm{O}$ monitoramento foi feito por coletas semanas, em 13 pontos distribuídos na área experimental. Os parâmetros analisados foram: temperatura, pH, turbidez, OD, DBO e DQO, cujos dados foram submetidos a estatística descritiva, análise de variância, teste de Tukey e espacialização por Geoestatística. Em relação às estruturas dos jardins, tanto as de bambu como as de palete que se mantiveram estáveis e flutuando, proporcionaram bom suporte para o desenvolvimento das plantas, tendo se destacado a Canna x generalis (Cana-da-índia) e o Cyperus papyrus (Papiro). Quanto aos parâmetros foram observadas reduções significativas de matéria orgânica nas três etapas. Considerando as limitações do projeto e as diversas interferências externas que o sistema esteve sujeito num ambiente não controlado, o mesmo se mostrou eficaz na remediação da poluição das águas do açude.

\section{Use of floating gardens in remediation of polluted urban surface waters}

\begin{abstract}
Enrichment by nutrients in water bodies that cause eutrophication is one of the major problems of the surface waters of urban basins, where this process is mainly a consequence of pollution by untreated effluent discharge. In view of the need for sustainable development of cities, there is a search for alternatives for the treatment of these polluted waters that can act in a harmonious way with the urban landscape. In this way, this work aims at the construction of a floating garden system capable of remediating the eutrophic waters of a small reservoir located at Campus Sede of Federal University of Campina Grande - PB ( $35^{\circ} 54^{\prime} 30^{\circ}$ W, $7{ }^{\circ}$ $12^{\prime} 58$ "S). The experiment was carried out in an area of $400 \mathrm{~m} 2$ of water mirror and the assembly of the garden system was divided into three stages, reaching a surface area coverage of approximately $10 \%$ at the end of the third stage. The modular structures were constructed of bamboo and pallets, using different species of aquatic and ornamental plants and organic substrate of coconut fiber. The monitoring was done by collections weeks, in 13 points distributed in the experimental area. The parameters analyzed were: temperature, $\mathrm{pH}$, turbidity, OD, BOD and COD, whose data were submitted to descriptive statistics, analysis of variance, Tukey test and spatialization by Geostatistics. In relation to the structures of the gardens, both bamboo and pallets that remained stable and floating, provided good support for the development of the plants, with Canna x generalis (Canaan) and Cyperus papyrus (Papyrus). Regarding the parameters, significant reductions of organic matter were observed in the three stages. Considering the limitations of the project and the various external interferences that the system was subjected in an uncontrolled environment, it was effective in remediation of the water pollution of the dam.
\end{abstract}

Keywords: Phytoremediation; Eutrophication; Artificial Floating Islands; Organic Substrates.

Topic: Engenharia Sanitária

Reviewed anonymously in the process of blind peer.

\section{Elis Gean Rocha (iD}

Universidade Federal de Campina Grande, Brasil http://lattes.cnpq.br/8907606848982197 http://orcid.org/0000-0003-1828-477X

\section{elisgean@hotmail.com}

\section{Patrícia Herminio Cunha Feitosa}

Universidade Federal de Campina Grande, Brasi

http://lattes.cnpq.br/8276706034302451

phcfeitosa@outlook.com

\section{Monica de Amorim Coura (D)}

Universidade Federal de Campina Grande, Brasil

http://lattes.cnpq.br/8234481367230599

http://orcid.org/0000-0001-5820-9315

macoura1@yahoo.com.br

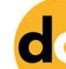

DOI: 10.6008/CBPC2179-6858.2018.007.0010
Received: 10/08/2018

Approved: 24/09/2018

\author{
Samara Rhúbia de Andrade Araújo Lima \\ Universidade Federal de Campina Grande, Brasil \\ http://lattes.cnpq.br/0079081900219495 \\ samaraand@live.com \\ William Paiva (i) \\ Universidade Estadual da Paraíba, Brasil \\ http://lattes.cnpq.br/2612977983185686 \\ http://orcid.org/0000-0003-0220-1247 \\ wpaiva461@gmail.com

\section{Andrea Carla Lima Rodrigues} \\ Universidade Federal de Campina Grande, Brasil \\ http://lattes.cnpq.br/2045007192282761 \\ andreaufcg@gmail.com
}

\section{Referencing this:}

ROCHA, E. G.; FEITOSA, P. H. C.; COURA, M. A.; PAIVA, W.; RODRIGUES, A. C. L.. Uso de jardins flutuantes na remediação de águas superficiais urbanas poluídas. Revista lbero Americana de Ciências Ambientais, v.9, n.7, p.98-109, 2018. DOI: http://doi.org/10.6008/CBPC2179-6858.2018.007.0010 


\section{INTRODUÇÃO}

Os sistemas de ilhas ou jardins flutuantes artificiais tem sido amplamente utilizados na recuperação de águas superficiais poluídas, devido a sua eficiência em assimilar nutrientes e criar condições favoráveis para a decomposição microbiana da matéria orgânica (ZHAO et al., 2012; WANG et al., 2009). Nakamura et al. (2008) destacam que o aprimoramento da qualidade da água é a característica mais importante dos jardins flutuantes. $\mathrm{Na}$ Ásia, onde houve instalações com grandes áreas de cobertura superficial, entre 10 e $30 \%$ em lagos e reservatórios, estes sistemas ajudaram a reduzir os efeitos da eutrofização.

Faulwetter et al. (2011) afirmam que ao comparar com outros sistemas de tratamento do tipo wetlands, o design das ilhas flutuantes baseia-se em informações ainda limitadas e a maioria das aplicações se mostram como únicas até para os parâmetros básicos como tamanho, grau de flutuabilidade, meios de plantação, seleção de plantas, entre outros. Os estudos de Headley et al. (2008), Nakai et al. (2010), Li et al. (2010) e Van de Moortel et al. (2010) são alguns dos poucos que tentaram avaliar o desempenho de ilhas flutuantes com experiências replicadas em ambientes controlados.

De acordo com Yeh et al. (2015) embora vários estudos tenham indicado a capacidade de remoção de poluentes dos sistemas compostos por plantas flutuantes, eles geralmente relataram eficiência com experiências de mesocosmo, em escala piloto. Segundo estes autores, há a necessidade de mais dados sobre a eficiência de remoção de nutrientes destes sistemas artificias em uma escala de campo. Dessa forma, este estudo teve como objetivo montar e avaliar a eficiência de um sistema de ilhas flutuantes quanto à remoção de matéria orgânica da água em uma área experimental de $400 \mathrm{~m}^{2}$ delimitada no açude do Campus Sede da Universidade Federal de Campina Grande, na Paraíba.

\section{METODOLOGIA}

O estudo foi desenvolvido no pequeno açude do Campus Sede da Universidade Federal de Campina Grande (UFCG), localizado no bairro Universitário do município de Campina Grande, Paraíba (3554'30" O e $7^{\circ} 12^{\prime} 58^{\prime \prime}$ S). A cidade está inserida na área geográfica de abrangência do semiárido brasileiro, definida pelo Ministério da Integração Nacional.

A precipitação anual média é de $804,9 \mathrm{~mm}$, com valores mensais concentrados (superiores a $100 \mathrm{~mm}$ ) durante os meses de março a julho, enquanto o trimestre de menor pluviometria varia de outubro a dezembro. 0 clima é tropical semiárido e apresenta temperaturas mais amenas durante todo o ano, variando de 16 a $32^{\circ} \mathrm{C}$, com umidade relativa do ar média de cerca de $80 \%$ (MACEDO et al., 2011). Segundo levantamento batimétrico realizado em agosto de 2016, o açude em estudo possui uma área de espelho d'água de aproximadamente $7.707,8 \mathrm{~m}^{2}$ e volume de $7.109 \mathrm{~m}^{3}$, com profundidades variando de 0,74 a 3,52m.

Tomando como exemplo os trabalhos de Zhu et al. (2011), Nakamura et al. (2008) e Headley et al. (2008), uma taxa de cobertura superficial de $10 \%$ foi estabelecida para a construção dos jardins. Delimitouse, após a saída do canal de drenagem principal, uma área de cerca de $400 \mathrm{~m}^{2}$ para a instalação do sistema, que foi construído em três etapas, até completar a taxa de cobertura desejada. Esta área foi escolhida por 
apresentar profundidades compatíveis com as necessidades dos jardins, entre 0,50 e 3,00m, possibilitando a flutuação e o acesso das raízes à coluna d'água.

Na primeira etapa do trabalho utilizou-se estrutura de bambu e nas outras duas, estruturas de paletes. Em cada etapa foi obtida uma parcela percentual de cobertura da área superficial, de modo que na terceira foi alcançada a taxa de $10 \%$ de ocupação. Na primeira etapa, foram construídos cinco jardins compostos por quatro módulos cada um, dois com dimensões de $1,50 \times 1,50 \mathrm{~m}^{2}$ e dois com $1,00 \times 1,00 \mathrm{~m}^{2}$, totalizando uma área de $32,5 \mathrm{~m}^{2}$. A montagem dos jardins teve duração de dois meses, sendo executada entre os meses de fevereiro a abril de 2017.

O suporte para o substrato de fibra da casca do coco foi feito com Tela F9 mosquiteiro costuradas aos bambus. As espécies de plantas utilizadas nesta etapa foram: Cyperus papyrus (papiro), Cyperus isocladus (mini papiro), Canna $x$ generalis (biri/cana da índia), Iris pseudacorus (íris-amarela), Tradescantia pallida (coração-roxo), Tradescantia zebrina.

Na segunda etapa foram montados mais cinco jardins, dois com $1,00 \times 1,00 \mathrm{~m}^{2}$, dois com $1,00 \times 1,20 \mathrm{~m}^{2}$ e um com $0,50 \times 0,60 \mathrm{~m}^{2}$, totalizando $4,7 \mathrm{~m}^{2}$. O processo de montagem durou uma semana do mês de junho de 2017 e compreendeu as seguintes etapas: separação e limpeza dos paletes, fixação da rede por meio de costura, preenchimento com o substrato de fibra de coco e inserção das plantas.

As espécies de plantas utilizadas nesta etapa foram: Cyperus papyrus (papiro), Canna $x$ generalis (biri/cana da índia), Iris pseudacorus (íris-amarela), Heliconia psittacorum (Heliconia papagaio), Spathiphyllum wallisii (Lírio da Paz) e grama. Na terceira e última etapa, a estrutura escolhida foi novamente

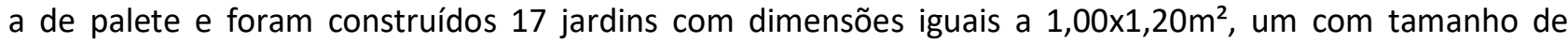
$1,05 \times 1,25 \mathrm{~m}^{2}$ e dois jardins de $1,10 \times 1,10 \mathrm{~m}^{2}$, totalizando $24,1 \mathrm{~m}^{2}$. O processo de montagem foi semelhante ao da segunda etapa, sendo iniciado em 08 de setembro e concluído em 22 de setembro de 2017.

$\mathrm{Na}$ terceira etapa, todos os paletes foram impermeabilizados e adicionadas garrafas pet para auxiliar na flutuação. As espécies de plantas utilizadas nesta etapa foram: Canna x generalis (biri/cana da índia), Iris pseudacorus (íris-amarela), Tradescantia pallida (coração-roxo), Epipremnum pinnatum (Jibóia) e Xanthosoma sagittifolium (Taioba). A Figura 1 mostra as estruturas montadas para os jardins nas três etapas. A estrutura de bambu feita na primeira (Figura 1A), estrutura de palete na segunda (Figura 1B), e estrutura de palete com garrafas pet na terceira etapa (Figura $1 C$ ), todas usando a fibra de coco como substrato para sustentação das plantas.

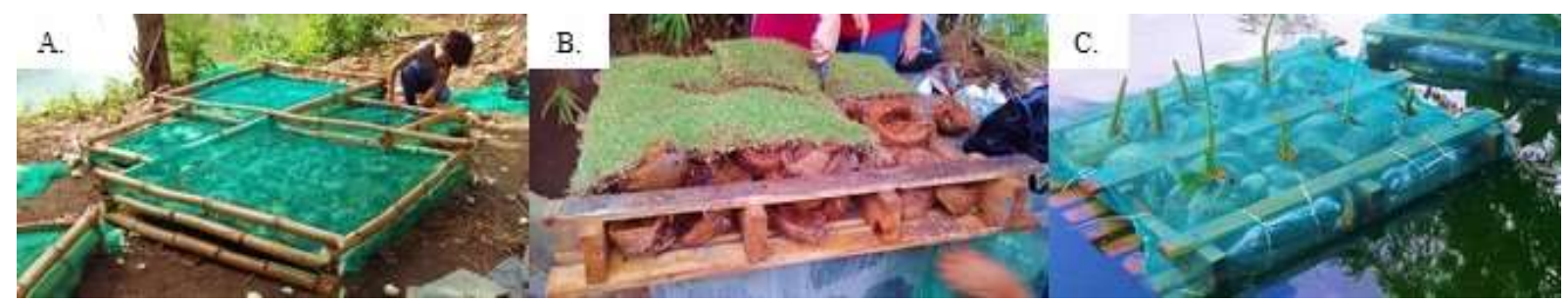

Figura 1: Estruturas dos jardins montadas nas três etapas.

Com o intuito de demarcar os pontos de coleta numa malha regular, foram dispostas 13 estacas de madeira na área experimental (Figura 2). A malha foi dividida em quadrados de $4,00 \times 4,00 \mathrm{~m}^{2}$ e as estacas 
distribuídas a cada 8,00m. A área de estudo recebe influência direta das atividades antrópicas, pois foi possível perceber que mesmo não havendo chuvas, é visto um lançamento constante de líquidos, através de tubulação, o que sugere uma contribuição irregular de esgotos com despejo direto no açude, além da contribuição vinda do canal. Além de tubos, as 3 principais fossas sépticas que atendem aos setores A, B e C da universidade estão localizadas nas imediações do corpo hídrico (Figura1), o que pode acarretar poluição do solo e das águas.

Devido a limitação dos equipamentos como modelo do barco, tipo de estaca, ação do vento e movimento das águas; os pontos não permaneceram com o espaçamento desejado, entretanto, conseguiuse manter distâncias aproximadas das planejadas, conforme apresentado no mapa dos pontos (Figura 2B), cujas coordenadas geográficas foram obtidas por meio de um GPS modelo GPSMAP ${ }^{\circledR} 76 C S x$.
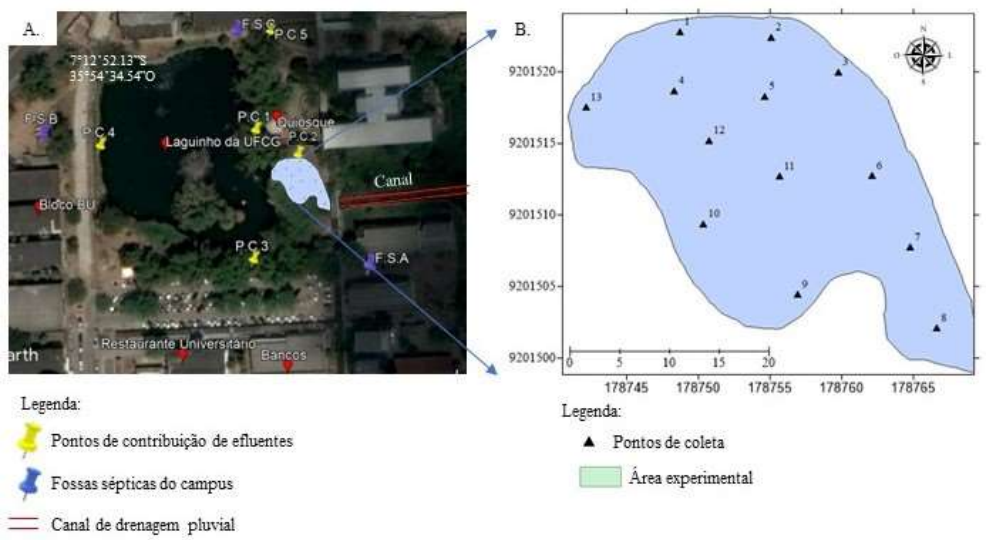

Figura 2: Área experimental e pontos de coleta.

Para avaliar quais os efeitos dos jardins flutuantes quanto à remoção de matéria orgânica da água, foram coletadas amostras de água nos primeiros $20 \mathrm{~cm}$ de profundidade, que corresponde à camada mais superficial do corpo d'água (epilímnio), durante o período de maio a dezembro de 2017. Os parâmetros avaliados foram Turbidez, pH, Temperatura, Oxigênio Dissolvido (OD), Demanda Bioquímica de Oxigênio $\left(\mathrm{DBO}_{5}\right)$, Demanda Química de Oxigênio (DQO), todos seguindo a metodologia proposta pelo Standard Methods for the Examination of Water and Wastewater (APHA, 2012). A análise estatística dos dados foi feita por meio de estatística descritiva, teste de variância (ANOVA- Fator único), teste de Tukey para comparação das médias e espacialização dos dados por interpolação IDW (Inverse Distance Weighted).

\section{RESULTADOS E DISCUSSÃO}

\section{Avaliação das estruturas de suporte dos jardins flutuantes e adaptação das plantas}

\section{Primeira etapa}

Durante o processo de construção dos jardins de bambu, as principais dificuldades encontradas foram a grande necessidade de mão de obra em todas as fases da montagem, manter o encaixe entre os bambus empilhados e garantir estabilidade à estrutura. Após alguns dias da inserção dos jardins na área 
experimental, foi possível perceber a necessidade de dar maior firmeza à rede durante a montagem, bem como aumentar o volume e adensamento do substrato.

Por efeito da absorção de água pelas fibras de coco, que conferiu aumento de peso à estrutura, a partir da primeira semana a rede começou a ceder e os jardins ficaram mais submersos. Este fato ocorreu

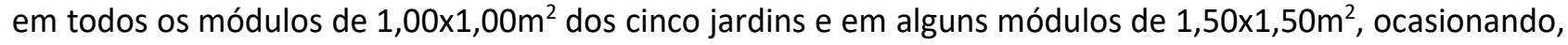
nestes casos, a não sobrevivência das plantas devido à inundação de parte das ilhas flutuantes. A ausência de mecanismos que auxiliassem na flutuação prejudicou a estabilidade dessas estruturas.

De todas as espécies colocadas nessa etapa, apenas o Cyperus papyrus (Papiro) se desenvolveu e sobreviveu até o final do estudo, pois os módulos $\left(1,50 \times 1,50 \mathrm{~m}^{2}\right)$ onde estas plantas foram colocadas ofereceram condições favoráveis ao seu desenvolvimento. As outras espécies não resistiram a partir do momento que as estruturas começaram a apresentar problemas, como foi o caso da Canna $x$ generalis (biri/cana da índia).

Nos módulos onde a rede obteve boa fixação do substrato, o mesmo foi suficiente para garantir o crescimento e estabilidade das plantas. Onde não foi identificado problemas quanto ao excesso de peso e falhas de flutuabilidade, as plantas se adaptaram. Algumas plantas que não se desenvolveram nos jardins que apresentaram curta durabilidade, foram novamente testadas nas etapas posteriores. Ao final desta etapa, dos cinco jardins instalados, apenas três continuaram flutuando e com vegetação. Os módulos com menor dimensão, $1,0 \times 1,0 \mathrm{~m}^{2}$, foram perdidos, desta forma, dos $32,5 \mathrm{~m}^{2}$ inicias restaram $16,5 \mathrm{~m}^{2}$ dos jardins com estrutura de bambu.

\section{Segunda etapa}

Nesta etapa, foram inseridos $4,7 \mathrm{~m}^{2}$ de jardins feitos com estrutura de palete e substrato da fibra da casca do coco, com o intuito de testar esta estrutura em ambiente não controlado e substituir parte da área de cobertura superficial perdida na primeira etapa. Comparando-se as estruturas de bambu, os paletes foram de fácil montagem, o que possibilitou a redução da mão de obra, além de serem mais econômicas e fixar melhor o substrato.

Todos os jardins instalados apresentaram boa adaptação no início da etapa, porém, devido ao excesso de peso ocasionado pelo crescimento das plantas, os mesmos começaram a afundar sendo posteriormente retirados do açude e recuperados. 0 processo de recuperação se deu pela retirada do excesso de plantas e adição de garrafas pet na parte inferior.

A Iris pseudacorus (íris amarela) obteve bom crescimento, atingindo cerca de $1,5 \mathrm{~m}$ de altura e as raízes se adaptaram bem ao substrato. Na recuperação foram feitas mudas de parte das plantas retiradas, sendo utilizadas nos jardins da terceira etapa. Da mesma forma que a íris amarela, a Canna $x$ generalis (cana da índia) também se desenvolveu bem, as raízes se adaptaram ao substrato e houve floração algumas vezes nesse período. As fases de crescimento da cana da índia, desde o dia da montagem em 26 de junho, cerca de dois meses depois com os caules e folhas bem desenvolvidos e uma semana depois quando as flores começaram a brotar, estão representadas na Figura 3A, 3B e 3C, respectivamente. 


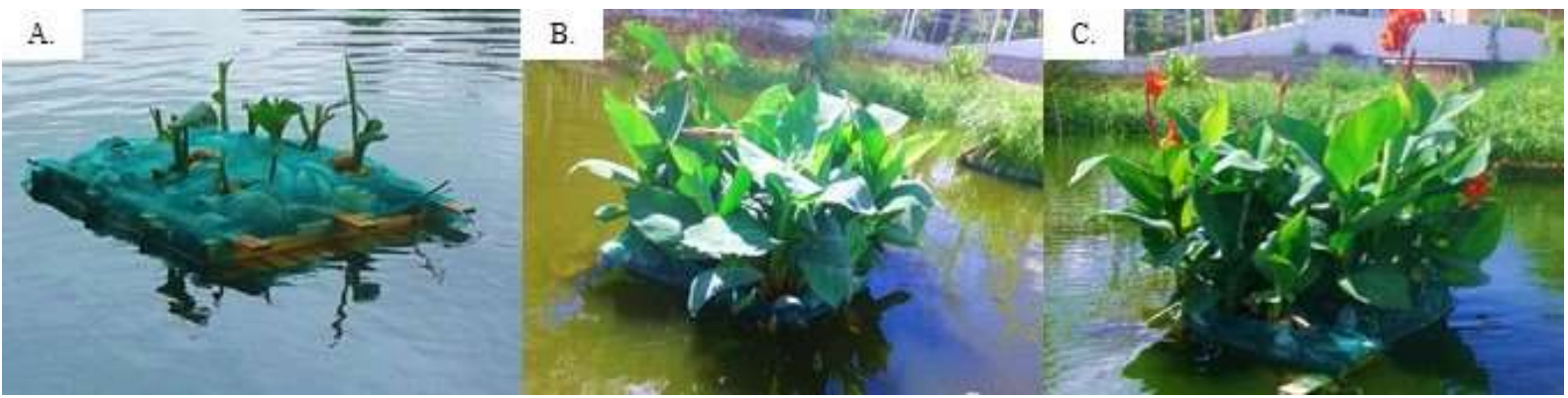

Figura 3: Estágios de desenvolvimento do jardim com palete e cana da índia.

\section{Terceira etapa}

Na terceira etapa foram inseridos mais vinte jardins com estrutura em palete, substrato de fibra de coco e garrafas pet para auxiliar à flutuação. As plantas que se adaptaram melhor nas duas etapas anteriores, com exceção do papiro foram também plantadas e novas espécies foram testadas. Assim como nas etapas anteriores, as estruturas que forneceram um ambiente estável tiveram uma resposta positiva quanto à adaptação e crescimento das plantas.

\section{Análise da qualidade da água}

As coletas foram realizadas no período na manhã, entre 8:00 e 10:00h. A temperatura média da água na área experimental acompanhou a variação da temperatura ambiental e não foi afetado pelas pequenas precipitações ocorridas durante o período de coleta, tendo variado de $22^{\circ} \mathrm{C}$ a $27^{\circ} \mathrm{C}$.

\section{pH}

O pH variou de 7,62 a 8,14 na primeira etapa, de 6,67 a 8,50 na segunda e de 7,08 a 9,09 na terceira, apresentando coeficientes de variação (CV) médios de 1,21\%, 1,69\% e 1,82\%, respectivamente, que segundo critérios da estatística são considerados de baixa variação, de acordo com a classificação de Gomes (1990), que estabelece como baixo, valores menores que 10\%, médio, entre 10 e 20\%; alto, entre 20 e $30 \%$; muito altos, superiores a 30\%. Van de Moortel (2008) avaliando um sistema de jardins em mesocosmos, encontrou valores de $\mathrm{pH}$ em torno de 7,21 e redução de 0,4 no pH quando comparado a prova em branco. O autor atribuiu esta redução à liberação de prótons e ácidos orgânicos expelidos pelas raízes das plantas na água.

Araújo (2017) encontrou, no açude estudado, valores médios de pH variando de 7,98 a 8,80, em período anterior a instalação do sistema dos jardins na área experimental. Assim, pode-se observar que após a implantação do sistema ocorreu uma redução de pH. Nesse contexto é possível observar que as plantas proporcionaram uma pequena redução do pH da água, não havendo alteração da sua condição alcalina.

\section{Turbidez}

De modo geral, os maiores valores de turbidez foram observados nos primeiros dias após a instalação do sistema. Alencar et al. (2017) estudando substratos orgânicos em sistemas flutuantes em tanques experimentais também observaram este fenômeno devido à perda de partículas dos substratos na água. 
Na primeira etapa deste estudo, a redução da turbidez média foi de $62 \%$, na segunda de $28 \%$ e na terceira de 51\%. Desta forma, é possível verificar a grande influência dos jardins na redução da turbidez, mesmo com o aumento desse parâmetro devido a fatores externos, e ao próprio jardim, que inicialmente também influencia devido ao desprendimento do substrato orgânico. Galisa (2016) avaliando o efeito dos jardins em escala piloto, utilizando a água do canal à montante do açude estudado, obteve eficiência máxima de remoção de turbidez de $87,9 \%$ utilizando substrato de fibra de coco.

Outro fator contribuinte para o incremento de turbidez no açude foi a ocorrência de eventos de chuva. Tomando como exemplo as duas maiores médias de turbidez durante o experimento, correspondentes a 41,0 e 54,2 UNT, medidos nos dias 18 de maio e 13 de junho, respectivamente, foram observados registros de precipitações em dias anteriores as datas de coleta. Em ecossistemas lacustres, onde a velocidade de escoamento da água é menor, a turbidez pode ser baixa, porém, como demostrado, as chuvas modificam a concentração deste parâmetro na água, seja aumentando por meio do carreamento de partículas ou reduzindo devido ao aumento da diluição.

Araújo (2017) em seu estudo de caracterização das águas do mesmo ecossistema encontrou valores de turbidez variando de 22,0 a 186,0 UNT. Os valores mais altos foram medidos entre novembro e dezembro de 2016, época em que o açude se encontrava com o volume bastante reduzido, havendo uma maior concentração de partículas em suspensão.

Ao avaliar a estatística descritiva dos dados, observou-se que os coeficientes de variação de turbidez foram elevados em grande parte dos dias monitorados. Na primeira etapa, o maior CV foi de $75,4 \%$, no dia 29 de junho, nesta data a turbidez mínima obtida foi 7,8 UNT no ponto 2, próximo a zona de saída do conjunto de jardins e máxima de 53,9 UNT no ponto 8 localizado na entrada da área experimental, que corresponde a chegada das águas do canal.

No início da segunda etapa a turbidez máxima foi de 127 UNT (medida no ponto 8), decaindo para 46,3 UNT (ponto 13). Ao final desta etapa, dia 01 de setembro, o CV foi de 10,7\% e a turbidez mínima de 28,9 UNT (ponto 8). Isto demostra que ocorrem mudanças significativas no comportamento da turbidez, tanto em relação ao tempo de monitoramento quanto à extensão da área experimental.

Na terceira etapa, a maior variação ocorreu no dia 19 de outubro, sendo igual a 62,3\%. A turbidez mínima, nesse dia, foi de 17,2 UNT (ponto 8) e máxima de 80,2 (ponto 2, localizado na margem direita do açude). Ao final desta etapa a turbidez sofreu redução, atingindo mínimo de 10,9 UNT e máximo e 20,7 UNT, medidos no dia 07 de dezembro.

O comportamento do parâmetro foi homogêneo em praticamente toda a área, mas nas regiões centrais observou-se uma turbidez ligeiramente menor. Esta redução pode ser atribuída à ação dos jardins, tanto pela limitação da produtividade primária, devido à sombra da área superficial, como pela absorção de partículas pelas plantas que estão desenvolvidas e capacidade de adsorção do substrato.

A turbidez média apresentou reduções significativas nas três etapas estudadas. Apesar de ser um parâmetro fortemente influenciado pelo escoamento superficial, devido ao carreamento de partículas, os jardins flutuantes atuaram na redução de partículas em suspensão e limitação da atividade fotossintética. 
Neste sentido, se destacam os dias 29 de junho, 27 de julho e 07 de dezembro, pertencentes a $1^{\underline{a}}$, $2^{\underline{a}}$ e $3^{\underline{a}}$ etapa, respectivamente.

\section{Avaliação da remoção de matéria orgânica da água}

As médias de OD alteraram de 1,7 a 5,7 mg/L, 4,9 a 11,7 mg/L e 3,7 a 5,5 mg/L na 1a , 2a e 3a etapa, respectivamente, indicando grande variação durante o período amostral. Os valores obtidos, com mínimo de $1,7 \mathrm{mg} / \mathrm{L}$ e máximo de $11,7 \mathrm{mg} / \mathrm{L}$, são explicados nos estudos limnológicos, pelas instabilidades dos ecossistemas lacustres eutrofizados. Na segunda etapa, onde o oxigênio apresentou as mais elevadas concentrações foi observada maior atividade fotossintética das algas. Nesta, a taxa de cobertura da área superficial pelo sistema de jardins foi menor que nas outras etapas.

$\mathrm{A} \mathrm{DBO}_{5}$ variou de 7 a $29 \mathrm{mg} / \mathrm{L}, 4$ a $31 \mathrm{mg} / \mathrm{L}$ e de 7 a $38 \mathrm{mg} / \mathrm{L}$, na 1a , 2a e 3a etapa, respectivamente (Tabela 1). O maior coeficiente de variação ocorreu na primeira etapa (48\%), seguido de $46 \%$ na segunda e $32 \%$ na terceira, valores estes considerados muito altos. O decaimento do CV ao longo das etapas está em consonância com o crescente aumento da área de cobertura superficial dos jardins.

A análise de variância aplicada a este parâmetro também mostrou diferenças significativas nas três etapas $(p<0,05)$. O teste de Tukey separou as médias em sete diferentes grupos. Os grupos de 1 a 5 reuniram médias de $\mathrm{DBO}_{5}$ variando de 11 a 25 mg/L, concentrando 87\% das medições (Tabela 1), o que evidencia uma $\mathrm{DBO}_{5}$ predominantemente baixa na área experimental.

Tabela 1: Estatística Descritiva e Teste de Tukey para as médias de $\mathrm{DBO}_{5}$.

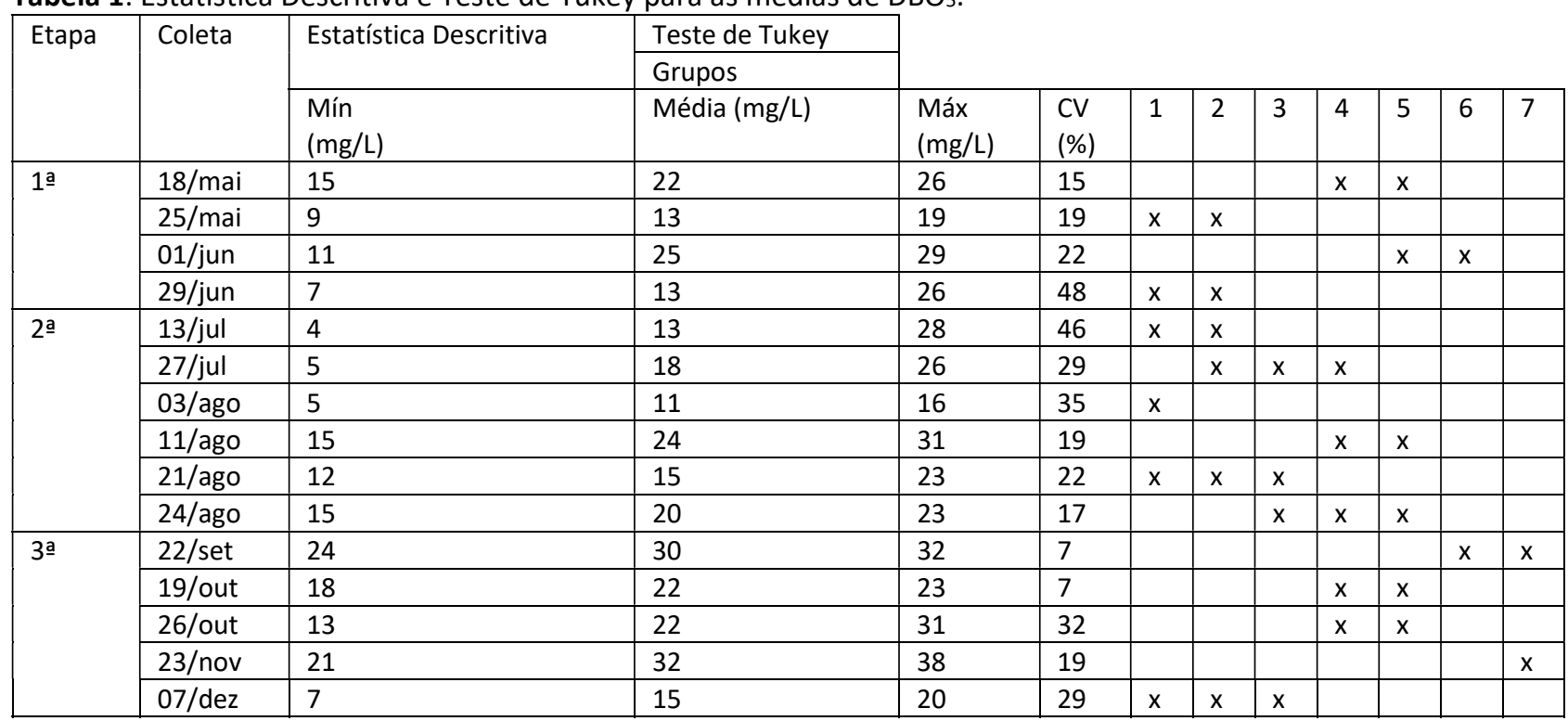

Os valores $\mathrm{DBO}_{5}$ não apresentaram comportamento consolidado. No entanto, pontualmente foi possível identificar reduções significativas em todas as etapas da pesquisa. A continuidade de coleta de dados após a terceira etapa poderia mostrar uma melhor redução deste parâmetro, uma vez que os jardins estariam mais desenvolvidos.

Sousa (2017) encontrou valor máximo de $\mathrm{DBO}_{5}$ igual a $52 \mathrm{mg} / \mathrm{L}$, no mesmo período deste estudo, na área alagada à montante do canal, no Campus Sede da UFCG. Neste local, ocorre o processo de depuração 
natural da matéria orgânica presente na água poluída recebida pela universidade através do sistema de drenagem de águas pluviais da cidade, havendo remoção de grande parte da $\mathrm{DBO}_{5}$ que chega ao açude.

Em estudo realizado em tanques experimentais utilizando a água do canal, à montante do açude, Galisa (2016) encontrou valor médio de $\mathrm{DBO}_{5}$ igual a $26 \mathrm{mg} / \mathrm{L}$, caracterizando esta água como um esgoto fraco. Do ponto de medida utilizado por este autor, até o açude, existem alguns mecanismos para promover a aeração da água, o que provoca uma degradação parcial da matéria orgânica.

Na pesquisa de Araújo (2017) entre novembro e dezembro de 2016 foram observados valores de $\mathrm{DBO}_{5}$ no açude de até $166 \mathrm{mg} / \mathrm{L}$, quando o nível do corpo hídrico estava muito baixo. Entretanto, no período de fevereiro a março de 2017, quando o açude se encontrava com volume máximo, a máxima $\mathrm{DBO}_{5}$ registrada foi de $46 \mathrm{mg} / \mathrm{L}$ e a mínima de $14 \mathrm{mg} / \mathrm{L}$. Esse decaimento pode ser explicado pela diluição da carga poluidora decorrente da chuva e o aumento da oxigenação da água. Em relação a DQO, em todas as etapas experimentais, os coeficientes de variação foram elevados, o que demostra grande variação nas medidas obtidas (Tabela 2).

Tabela 2: Estatística Descritiva e Teste de Tukey para as médias de DQO.

\begin{tabular}{|c|c|c|c|c|c|c|c|c|c|c|c|c|}
\hline \multirow[t]{3}{*}{ Etapa } & \multirow[t]{3}{*}{ Coleta } & \multirow[t]{2}{*}{ Estatística Descritiva } & \multirow{2}{*}{$\begin{array}{l}\text { Teste de Tukey } \\
\text { Grupos }\end{array}$} & \multirow[b]{3}{*}{$\begin{array}{l}\text { Máx } \\
(\mathrm{mg} / \mathrm{L})\end{array}$} & \multirow[b]{3}{*}{$\begin{array}{l}\mathrm{CV} \\
(\%)\end{array}$} & \multirow[b]{3}{*}{1} & \multirow[b]{3}{*}{2} & \multirow[b]{3}{*}{3} & \multirow[b]{3}{*}{4} & \multirow[b]{3}{*}{5} & \multirow[b]{3}{*}{6} & \multirow[b]{3}{*}{7} \\
\hline & & & & & & & & & & & & \\
\hline & & $\begin{array}{l}\text { Mín } \\
\text { (mg/L) }\end{array}$ & Média (mg/L) & & & & & & & & & \\
\hline \multirow[t]{4}{*}{$1 \underline{a}$} & $15 / \mathrm{mai}$ & 85 & 132 & 182 & 17 & & $x$ & $x$ & $x$ & & & \\
\hline & $25 / \mathrm{mai}$ & 100 & 136 & 260 & 32 & & $x$ & $x$ & $x$ & & & \\
\hline & 01/jun & 8 & 52 & 94 & 80 & $x$ & & & & & & \\
\hline & $13 /$ jul & 18 & 102 & 212 & 41 & $x$ & $x$ & $x$ & & & & \\
\hline \multirow[t]{6}{*}{$2 \underline{a}$} & $27 / \mathrm{jul}$ & 98 & 166 & 226 & 22 & & & & $x$ & $x$ & & \\
\hline & 03/ago & 94 & 197 & 291 & 33 & & & & & $x$ & & \\
\hline & 11/ago & 345 & 368 & 413 & 6 & & & & & & & $\mathrm{x}$ \\
\hline & 21/ago & 70 & 121 & 298 & 47 & & $x$ & $x$ & $x$ & & & \\
\hline & 24/ago & 90 & 124 & 204 & 25 & & $x$ & $x$ & $x$ & & & \\
\hline & $01 /$ set & 123 & 166 & 203 & 16 & & & & $x$ & $x$ & & \\
\hline \multirow[t]{7}{*}{$3 \underline{a}$} & $15 /$ set & 37 & 91 & 175 & 41 & $x$ & $x$ & $x$ & & & & \\
\hline & 19/out & 29 & 76 & 112 & 24 & $\mathrm{x}$ & $x$ & & & & & \\
\hline & 26/out & 102 & 138 & 215 & 21 & & & $x$ & $x$ & $x$ & & \\
\hline & $02 /$ nov & 84 & 140 & 534 & 83 & & & $x$ & $x$ & $x$ & & \\
\hline & $08 /$ nov & 71 & 99 & 128 & 21 & $x$ & $x$ & $x$ & & & & \\
\hline & $23 /$ nov & 243 & 278 & 304 & 7 & & & & & & $x$ & \\
\hline & 07/dez & 58 & 85 & 142 & 27 & $x$ & $x$ & $x$ & & & & \\
\hline
\end{tabular}

As faixas de variação da concentração de DQO foram de 8 a 260 mg/L, 70 a 413 mg/L e 29 a 534 mg/L,

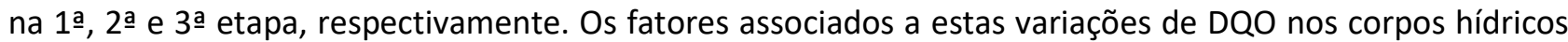
estão relacionados ao lançamento de esgotos domésticos e de origem industrial, lançados indevidamente em cargas intermitentes, no sistema de drenagem.

Com a utilização do teste de Tukey, as médias de DQO foram classificadas em sete grupos distintos. Os grupos de 1 a 5 reuniram $88 \%$ dos dados e os 6 e 7 apenas $12 \%$ deles. Desse modo podemos observar que as médias de DQO variaram prioritariamente de 52 a $197 \mathrm{mg} / \mathrm{L}$ (Tabela 2). Os resultados da interpolação das concentrações médias de cada ponto avaliado na área experimental nas três etapas, para a $\mathrm{DBO}_{5}$ e $\mathrm{DQO}$, estão representados nos mapas da Figura 4. Estes mapas mostram o comportamento desses dois parâmetros no estudo. 
A Figura 4A mostra que, na primeira etapa, a $\mathrm{DBO}_{5}$ estava superior a $19 \mathrm{mg} / \mathrm{L}$ na entrada da área do sistema de jardins montados, sofrendo reduções mais significativas na margem superior direita e inferior esquerda, enquanto na parte central e na saída da área experimental não foram observadas grandes variações deste parâmetro.
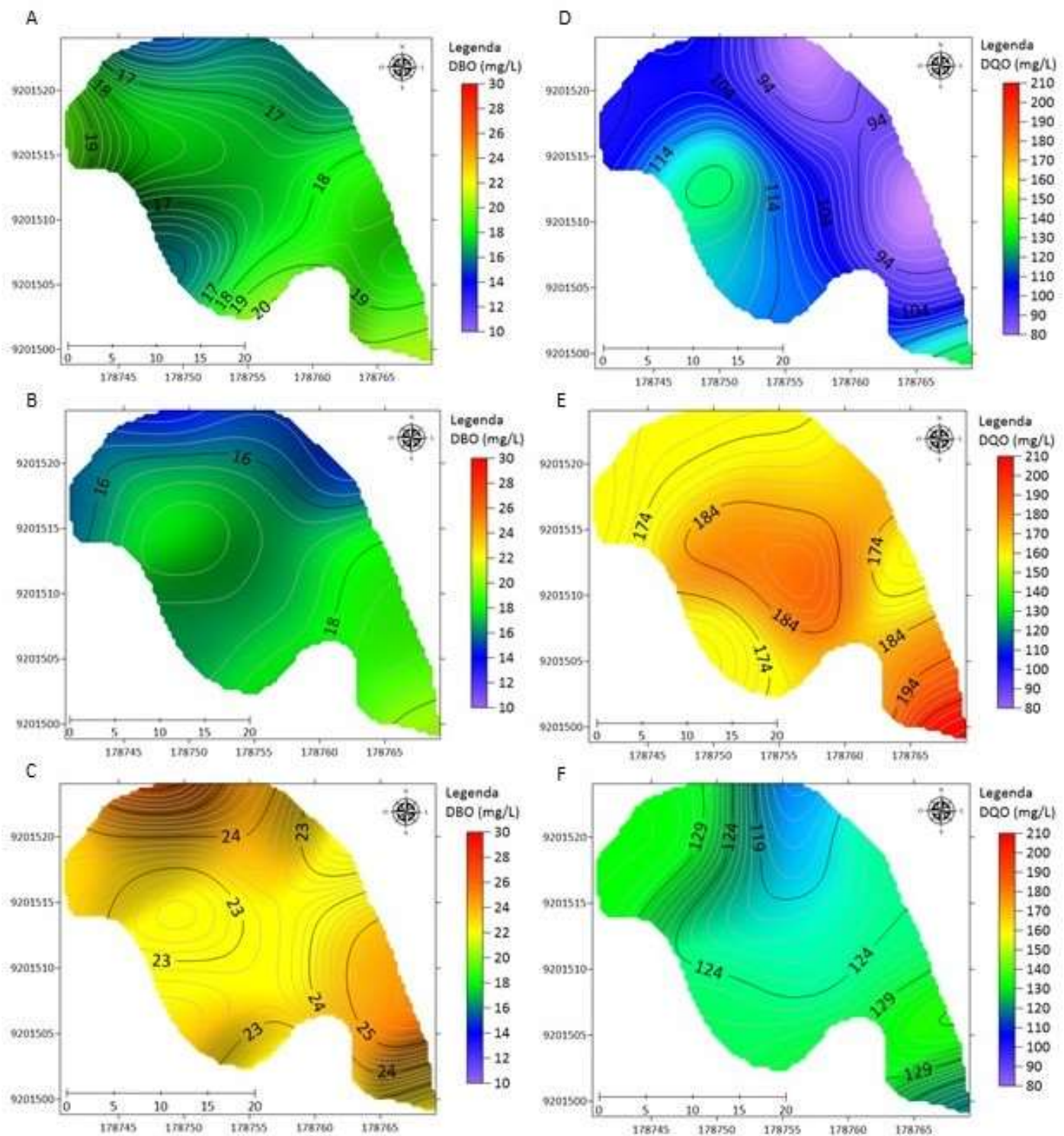

Figura 4: Mapas das concentrações médias de $\mathrm{DBO}_{5}$ e $\mathrm{DQO}$ nas três etapas do estudo.

A DQO na primeira etapa (Figura 4D), mostra reduções de concentração em toda margem direita, com valores abaixo de $90 \mathrm{mg} / \mathrm{L}$, enquanto os valores de entrada eram superiores a $130 \mathrm{mg} / \mathrm{L}$, voltando a aumentar do centro para a margem esquerda. Na segunda etapa, houve uma redução significativa da $\mathrm{DBO}_{5}$ na área mais distante da saída do canal (Figura 4B). Nesta etapa, a DQO também foi menor nesta área, apresentando redução em toda a extensão, se comparada à saída do canal.

$\mathrm{Na}$ terceira etapa a concentração de $\mathrm{DBO}_{5}$ foi homogênea em toda área, apresentando valores menores na área central, assim como a DQO, que reduziu significativamente da saída do canal para a área central e margem direita, como diferença de aproximadamente $10 \mathrm{mg} / \mathrm{L}$, voltando a aumentar na saída da área experimental. 
Os diversos estudos sobre sistemas de jardins flutuantes realizados em mesocosmos e tanques experimentais, comprovaram a eficiência desses sistemas na remediação de água poluídas. No entanto, em um ambiente natural, não controlado, a avaliação da ação dos jardins na melhora da qualidade de água se torna mais complexa, devido às diversas interferências ambientais que este ecossistema está sujeito, ampliando a necessidade de pesquisas nesses espaços, de forma a consolidar métodos de fitorremediação em corpos hídricos que sofrem fortes influências das atividades antrópicas.

Quanto a matéria orgânica, os dados de $\mathrm{DBO}_{5}$ não apresentaram um comportamento consolidado, porém houve reduções significativas em vários dias monitorados. A partir da espacialização dos dados, foi possível observar o decaimento da demanda na área de estudo, como também identificar como as diversas entradas de efluentes no açude interferem na quantidade de matéria orgânica presente na água da área experimental.

De modo geral, a $\mathrm{DBO}_{5}$ foi baixa, tendo valor máximo igual a $38 \mathrm{mg} / \mathrm{L}$. A matéria orgânica é substancialmente reduzida à montante do açude, devido a depuração que ocorre na área alagada e aos mecanismos físicos de oxigenação da água presentes no canal, chegando ao açude em menores concentrações.

A DQO, também apresentou decaimento significativo em alguns dias monitorados, apresentando redução na extensão da área experimental. No dia 03 de agosto, por exemplo, a $\mathrm{DBO}_{5}$ e a DQO tiveram uma concentração na saída do sistema menor que na entrada, apesar do comportamento não ser similar para os dois parâmetros na área estudada. A dinâmica do processo de remoção de matéria orgânica levou a uma taxa positiva de redução das demandas de oxigênio na área experimental.

\section{CONCLUSÕES}

As estruturas construídas com bambu foram de difícil montagem, apesentando problemas que comprometeram a sobrevivência de algumas das espécies de plantas colocadas. Os jardins feitos com bambu que não afundaram, forneceram as plantas boas condições de crescimento e daptação ao ambiente.

As estruturas de jardins feitas de paletes se mostraram como uma boa alternativa, se adicionadas garrafas pet para auxiliar na flutuação. Das espécies de plantas utilizadas em todas as etapas, as que melhor se adaptaram ao sistema construído foram: Cyperus papyrus (papiro), Canna x generalis (biri/cana da índia), Iris pseudacorus (íris-amarela), e Xanthosoma sagittifolium (taioba).

Os jardins flutuantes atuaram na redução de partículas em suspensão e limitação da atividade fotossintética, contribuindo nas reduções significativas de turbidez nas três etapas. No período do experimento não foi possível estabelecer taxas de redução de matéria orgânica de forma gradual, mas foram obtidas reduções significativas de DBO5 e DQO em alguns dias de monitoramento na área em estudo.

\section{REFERÊNCIAS}

ARAÚJO, C. T. F.. Caracterização das águas do açude da Universidade Federal de Campina Grande e classificação preliminar para usos diversificados. Monografia (Trabalho de Conclusão de Curso em Engenharia Civil) - Universidade Federal de Campina Grande, Campina Grande, 2017. 
ALENCAR, S. L. F.; FEITOSA, P. H. C.. Uso de jardins flutuantes como ferramenta de gestão em açudes urbanos e embelezamento das cidades - Estudo do 'Laguinho' do campus Campina Grande da UFCG. In: CONGRESSO DE INICIAÇÃO CIENTÍFICA DA UNIVERSIDADE FEDERAL DE CAMPINA GRANDE, 14. Anais. Campina Grande, 2017.

APHA. American public health association. Standard methods for the examination of water and wasterwater. 22 ed. Sprimgfield: Byrd Prepress, 2012.

FAULWETTER, J. L.. Floating treatment wetlands for domestic wastewater treatment. Water Science \& Technology, v.64, n.10, p.208-2095, 2011. DOI: http://doi.org/10.2166/wst.2011.576

GALISA, D. R. R.. Utilização de jardins flutuantes no tratamento de águas superficiais urbanas. Monografia (Trabalho de Conclusão de Curso em Engenharia Civil) Universidade Federal de Campina Grande, Campina Grande, 2017.

GOMES, F. P.. Curso de Estatística Experimental. Piracicaba: ESALQ/USP, 1985.

HEADLEY, T. R.; TANNER, C. C.. Floating treatment wetlands for the removal of fine particulates, copper and zinc from stormwater. In: INTERNATIONAL CONFERENCE ON WETLAND SYSTEMS FOR WATER POLLUTION CONTROL, INDORE, 11. Anais. 2008. p.655-659.

LI, X.-N.; SONG, H-L.; LI, W.; LU, X-W.; NISHIMURA, O.. An integrated ecological floating-bed employing plant, freshwater clam and biofilm carrier for purification of eutrophic water. Ecological Engineering, v.36, n.4, p.382390, 2010. DOI:

http://doi.org/10.1016/j.ecoleng.2009.11.004

MACEDO, M. J. H.; GUEDES, R. V. S.; SOUSA, F. A. S.. Monitoramento e intensidade das secas e chuvas na cidade de Campina Grande/PB. Revista Brasileira de Climatologia, v.8, p.105-117, 2011. DOI: http://dx.doi.org/10.5380/abclima.v8i0.25797

NAKAI, S.; ZOU, G.; SONG, X.; PAN, Q.; ZHOU, S.; HOSOMI, $M$.. Release of anticyanobacteria allelochemicals from aquatic and terrestrial plants applicable for artificial floating islands. Journal of Water and Environment Technology, v.6, n.1, p.55-63, 2008. DOI:

http://doi.org/10.2965/iwet.2008.55

NAKAMURA, K.; MULLER, G.. Review of the performance of the artificial floating island as are storation tool for aquatic environments. In: WORLD ENVIRONMENTAL AND WATER RESOURCES CONGRESS. Anais. Ahupua'a, 2008. DOI: http://doi.org/10.1061/40976(316)276

SOUZA, S. C. R.. Tolerância aos metais pesados chumbo e zinco e potencial fitorremediador de mudas de espécies arbóreas. Dissertação (Mestrado em Biologia Vegetal) Universidade Estadual de Campinas, Campinas, 2010.

VAN DE MOORTEL, A.. Use of floating macrophyte mats for treatment of CSOs. In: INTERNATIONAL CONFERENCE ON URBAN DRAINAGE, 11. Anais. Edinburg, 2008.

VAN DE MOORTEL, A. MEERS, N.; PAUW, N.; TACK, F. M. G.. Effects of vegetation, season, and temperature on the removal of pollutants in experimental floating treatment wetlands. Water Air and Soil Pollution, v.212, n.1-4, p.281297, 2010. DOI: http://doi.org/10.1007/s11270-010-0342-z

YEH, N.; YEH, P.; CHANG, Y-H.. Artificial floating islands for environmental improvement. Renewable and Sustainable Energy Reviews, v.47, p.616-622, 201. DOI: http://doi.org/10.1016/i.rser.2015.03.090

WANG, G. X.; ZHANGB, L. M.; CHUAC, H.; LI, X. D.; XIAB, M. F.; PUA, P. M.. A mosaic community of macrophytes for the ecological remediation of eutrophic shallow lakes. Ecological Engineering, v.35, n.4, p.582-590, 2009. DOI: http://doi.org/10.1016/j.ecoleng.2008.06.006

ZHAO, F.; XI, S.; YANG, X.; YANG, W.; LI, J.; GU, B.; HE, Z. Purifyng eutrophic river waters with integrated floating islands systems. Ecological Engineering, v.40, p.53-60, 2012. DOI: http://doi.org/10.1016/j.ecoleng.2011.12.012

ZHU, L.; LI, Z.; KETOLA, T.. Biomass accumulations and nutrient uptake of plants cultivated on artificial floating beds in China's rural área. Ecological Engineering, v.37, n.10, p.1460-1466, 2011. DOI: http://doi.org/10.1016/j.ecoleng.2011.03.010

A CBPC - Companhia Brasileira de Produção Científica (CNPJ: 11.221.422/0001-03) detém os direitos materiais desta publicação. Os direitos referem-se à publicação do trabalho em qualquer parte do mundo, incluindo os direitos às renovaç̃ões, expansões e disseminações da contribuição, bem como outros direitos subsidiários. Todos os trabalhos publicados eletronicamente poderão posteriormente ser publicados em coletâneas impressas sob coordenação da Sustenere Publishing, da Companhia Brasileira de Produção Científica e seus parceiros autorizados. Os (as) autores (as) preservam os direitos autorais, mas não têm permissão para a publicação da contribuição em outro meio, impresso ou digital, em português ou em tradução. 